\title{
Siliconelonic Liquid Elastomer Composite with Keratin as Reinforcing Agent Utilized as Pressure Sensor
}

\author{
Liu, Xue; Yu, Liyun; Zhu, Zicai; Nie, Yi; Skov, Anne Ladegaard
}

Published in:

Macromolecular Rapid Communications

Link to article, DOI:

$10.1002 /$ marc.202000602

Publication date:

2021

Document Version

Early version, also known as pre-print

Link back to DTU Orbit

Citation $(A P A)$ :

Liu, X., Yu, L., Zhu, Z., Nie, Y., \& Skov, A. L. (2021). Siliconelonic Liquid Elastomer Composite with Keratin as Reinforcing Agent Utilized as Pressure Sensor. Macromolecular Rapid Communications, 42(5), [2000602]. https://doi.org/10.1002/marc.202000602

\section{General rights}

Copyright and moral rights for the publications made accessible in the public portal are retained by the authors and/or other copyright owners and it is a condition of accessing publications that users recognise and abide by the legal requirements associated with these rights.

- Users may download and print one copy of any publication from the public portal for the purpose of private study or research.

- You may not further distribute the material or use it for any profit-making activity or commercial gain

- You may freely distribute the URL identifying the publication in the public portal 


\title{
WILEY-VCH
}

\section{Silicone-ionic liquid elastomer composite with keratin as reinforcing agent utilized as pressure sensor}

Xue Liu, Liyun Yu, Zicai Zhu, Yi Nie*, Anne Ladegaard Skov*

Xue Liu, Dr. Liyun Yu, Prof. Anne Ladegaard Skov

Danish Polymer Center, Department of Chemical and Biochemical Engineering, Technical

University of Denmark, 2800 Kgs. Lyngby, Denmark

Xue Liu, Prof. Yi Nie

Beijing Key Laboratory of Ionic Liquids Clean Process, Institute of Process Engineering, Chinese Academy of Sciences, Beijing, 100190, China

Prof. Yi Nie

Zhengzhou Institute of Emerging Industrial Technology, Zhengzhou, 450000, China

Prof. Zicai Zhu

Shanxi Key Laboratory of Intelligent Robots, Xi'an Jiaotong University, Xi'an, 710049, China

Email: al@kt.dtu.dk, ynie@ipe.ac.cn

\begin{abstract}
Development of a flexible pressure sensor is crucial for the future improvement of the wearable electronic devices designed to detect dynamic human motion. In this study, a novel pressure sensor with remarkably improved force sensing characteristics is obtained through combined usage of polydimethylsiloxane (PDMS) and ionic liquid (IL). Keratin is dispersed homogeneously in the PDMS matrix to serve as a reinforcing filler. High conductivity IL is employed as sensitivity-enhancing constituent in the elastomer, and the effect of the amount of IL on elastomers' pressure-sensing performance is investigated. The elastomer with 70 parts per hundred rubber (phr) IL shows excellent pressure-sensing performance. This novel pressure sensor demonstrates high linear sensitivity $\left(0.037 \mathrm{kPa}^{-1}\right)$ in the large pressure region of $0-10$ $\mathrm{kPa}$. Response and recovery times are $8 \mathrm{~ms}$ and $11 \mathrm{~ms}$, respectively, which are much shorter than previously reported. Moreover, the pressure sensor could distinguish different pressures via stable sensing signals in the pressure range of 0 to $50 \mathrm{kPa}$. The excellent performance of the novel pressure sensor has application potential in various fields, such as health monitoring and soft robotics.
\end{abstract}

Keywords: PDMS, ionic liquid, keratin, pressure sensor, fast response 


\section{WILEY-VCH}

\section{Introduction}

Flexible and soft pressure sensors have attracted significant attention for their applications in various fields, such as soft robotics, ${ }^{[1]}$ wearable electronic devices, ${ }^{[2]}$ and energy storage ${ }^{[3]}$ The ability to sense low pressure $(1-10 \mathrm{kPa})$, which is an important range covering intra-body pressure, is particularly important for pressure sensors. ${ }^{[4]}$ In recent years, vast efforts have been made to improve the performance of pressure sensors: e.g., via the integration of polymers with various nanomaterials including carbon nanotubes, ${ }^{[5]}$ gold/silver nanowires, ${ }^{[6]}$ graphene nanosheets, ${ }^{[7]}$ and metal nanoparticles. ${ }^{[8]}$ While the structures and materials of these novel pressure sensors are different, they all typically operate based on force-induced changes in piezoresistivity, capacitance, piezoelectricity and iontronic. ${ }^{[4,9]}$ For example, Qin et al. prepared a pressure sensor by integrating hydrophobic carbon nanotubes into hydrophobically associated polyacrylamide hydrogel, reaching a sensitivity of $0.127 \mathrm{kPa}^{-1}$ in the large-pressure region of 0-50 $\mathrm{kPa}^{[5]}$ Lee et al. realized an ultra-robust, wide-range pressure sensor based on polyurethane foam coated with both conformal silicone rubber and CNT/TPU nanocomposite islands, the sensitivity of which was controlled from $0.013 \mathrm{kPa}^{-1}$ to $0.032 \mathrm{kPa}^{-1}$. ${ }^{[10]}$

Even though pressure sensors fabricated by incorporating nanomaterials into polymers show high sensitivity, they consequently display limited stretchability and long response times, thereby significantly limiting their applications. In order to produce an improved smart wearable sensor, it is therefore necessary to develop a highly stretchable and flexible sensor with short response and recovery times.

Silicone elastomers represent an excellent matrix for sensors due to their high stretchability and flexibility, ${ }^{[11]}$ as well as their inherent physical and chemical stability ${ }^{[12]}$ even at elevated temperatures. ${ }^{[13]}$ Ionic liquids (ILs), which have high conductivity, low viscosity and chemical stability, were also considered as excellent material candidates for the development of novel, 


\section{WILEY-VCH}

improved pressure sensors. ${ }^{[14]}$ However, the electromechanical instability of pure ILs limits their application as pressure sensors and require a mechanically robust matrix. Iontronic pressure sensors based on polymer-IL composites and possessing both the elasticity of the elastomer and the electrical conduction of the ILs have therefore received significant attention from researchers. ${ }^{[15]}$ For example, a flexible capacitive pressure sensor that incorporates micropatterned pyramidal ionic gel was fabricated which showed excellent pressure sensitivity and a broad sensing range ${ }^{[16]}$ Despite the great progress in the iontronic pressure sensor achieved so far, the development of iontronic pressure sensor is still limited due to the complicated fabrication process, high cost, and small linear response range.

Herein, a novel high-performance pressure sensor was fabricated by incorporating 1-butyl3-methylimidazolium hexafluoroantimonate $\left(\mathrm{BmimSbF}_{6}\right)$ into polydimethylsiloxane (PDMS) elastomers. Wool keratin, which has high biodegradability, biocompatibility, and stability, was added as a reinforcing filler. In addition to improving the performance of the material as pressure sensor this method also provides a simplified preparation scheme with great potential for the large-scale production of ionic materials. Different loading amounts of $\mathrm{BmimSbF}_{6}$ were tested in order to produce an optimized pressure sensor with excellent mechanical properties, high force sensing characteristics, and a wide linearity pressure range. More specifically, the optimized sensor demonstrated a sensitivity of $0.037 \mathrm{kPa}^{-1}$ at pressures below $10 \mathrm{kPa}$ and a sensitivity of $0.003 \mathrm{kPa}^{-1}$ in the range between $10 \mathrm{kPa}^{-1}$ and $50 \mathrm{kPa}^{-1}$. Finally, the response time of the $70 \mathrm{phr} \mathrm{BmimSbF}_{6}$-loaded pressure sensor showed a response time of $8 \mathrm{~ms}$ to a pressure input of $1.6 \mathrm{kPa}(0.04 \mathrm{~N})$ and a recovery time of $11 \mathrm{~ms}$, which is much shorter than previously reported.

\section{Results and discussion}

\subsection{Fabrication of IL-loaded pressure sensor.}

Figure 1 illustrates the complete manufacturing process of the $\mathrm{BmimSbF}_{6}$-loaded pressure 


\section{WILEY-VCH}

sensor. Vinyl-terminated DMS-V31, cross-linker HMS-30 and the catalyst (Pt 511) were mixed using a SpeedMixer. Wool keratin was used as a replacement for $\mathrm{SiO}_{2}$ as reinforcing filler. $\mathrm{BmimSbF}_{6}$ (volume fractions varied from 0 to $44 \%$, see supplementary information (SI) Table S1) was then added as liquid filler, and the mixture was speed mixed again. Structures are shown in SI Figure S1. The system of ionic liquid and elastomer has been investigated in a previous study. ${ }^{[17]}$ The homogeneous mixture obtained was then coated as a film and cured in the oven at $80{ }^{\circ} \mathrm{C}$ for $2 \mathrm{~h}$. Copper sheets were attached to the two surfaces of the film as electrodes, and specimens were investigated using a voltage response test as described in the experimental section in SI.

\subsection{Properties of IL-loaded elastomer films.}

FT-IR spectra were acquired in order to verify successful $\mathrm{BmiSbF}_{6}$ loading into the silicone elastomer. For films into which $\mathrm{BmimSbF}_{6}$ has been successfully incorporated, the FT-IR spectra display a characteristic imidazole ring peak at $1580 \mathrm{~cm}^{-1}$ (SI Figure S2). Furthermore, the SEM images show that the ionic liquids (black dots) and keratin powders (white dots) are well-dispersed throughout the silicone network (SI Figure S3).

Gel fractions of the films were investigated in order to analyze the amount of bonded (gel fraction) and non-bonded (sol fraction) species in the elastomer network. The measured gel fractions of films with various $\mathrm{BmimSbF}_{6}$ concentrations are shown in Figure 2a, demonstrating that the gel fractions of the films decreased with an increased loading amount of $\mathrm{BmimSbF}_{6}$, which can be explained by the increased inhibiting effect of the IL at higher concentrations.

A comparison of the mechanical properties of pure PDMS film with $\mathrm{SiO}_{2}$ and pure PDMS film with keratin is shown in SI Figure S4. Films with keratin as filler displayed similar mechanical properties to films with $\mathrm{SiO}_{2}$ as filler which is an interesting finding since it indicates that keratin can replace $\mathrm{SiO}_{2}$ as a solid filler to enhance the mechanical properties of 


\section{WILEY-VCH}

the film. This can potentially have great impact in making silicone elastomers more sustainable. However, this is not the scope of the current article.

The tensile stress-strain curves for PDMS-based films with various $\mathrm{BmimSbF}_{6}$ amounts are presented in SI Figure S5, while the corresponding Young's modulus and tensile strengths are depicted in Figure 2b and Figure 2c, respectively. It is clear that the tensile strength and Young's modulus of the BmimSbF-loaded films are lower than those of the pure PDMS film, and that the tensile strength and Young's modulus decreased with increasing amount of $\mathrm{BmimSbF}_{6}$. With an increase of $\mathrm{BmimSbF}_{6}$ amount from 0 to $5 \mathrm{phr}$, both the tensile strain and Young's modulus decreased significantly, indicating that ionic liquid fillers act as softeners in the system, so that their addition effectively enhances the flexibility of the elastomer materials.

\subsection{Pressure responses of IL-loaded sensors.}

A dedicated test bench was designed to evaluate pressure sensor performance, as illustrated in Figure 1. The operation principle of the pressure sensor is analogue with the previously reported operational principle of iontronic pressure sensors, ${ }^{[9]}$ and a schematic illustration is shown in SI Figure S6. In order to describe the effect of $\mathrm{BmimSbF}_{6}$ on the sensing performance of the investigated films, the voltage change curves for elastomers with different $\mathrm{BmimSbF}_{6}$ amounts in response to an instantaneous pressure input of $40 \mathrm{kPa}(1.0 \mathrm{~N})$ are compared in Figure 3a. A tunable voltage change depending on the loading amount of $\mathrm{BmimSbF}_{6}$ was observed, with the $70 \mathrm{phr} \mathrm{BmimSbF}_{6}$-loaded sensor exhibiting the highest voltage change due to the increased charge density with increased IL loading. ${ }^{[9]}$ This behavior confirms that the amount of $\mathrm{BmimSbF}_{6}$ is vital to improving pressure sensor sensitivity. As Figure 3b shows, the $70 \mathrm{phr} \mathrm{BmimSbF}_{6}$-loaded pressure sensor has a high sensitivity of $0.037 \mathrm{kPa}^{-1}\left(1.56 \mathrm{~N}^{-1}\right)$ in the range of $0-10 \mathrm{kPa}$, while the sensitivity declines with increasing pressure in the high pressure range ( $\mathrm{S} 2=0.003 \mathrm{kPa}^{-1}, 0.12 \mathrm{~N}^{-1}$ ), and the sensitivity is much higher than that of $50 \mathrm{phr}$ BmimSbF 6 -loaded pressure sensor $\left(0.001 \mathrm{kPa}^{-1}\right.$; SI Figure S7), further indicating that the 


\section{WILEY-VCH}

importance of $\mathrm{BmimSbF}_{6}$ as critical to the sensitivity of the pressure sensor.

An additional advantage of the $\mathrm{BmimSbF}_{6}$-loaded pressure sensor is that it responds quickly to applied pressure. As shown in Figure 3c, the $70 \mathrm{phr} \mathrm{BmimSbF}_{6}$-loaded pressure sensor responds to a pressure input of $1.6 \mathrm{kPa}(0.04 \mathrm{~N})$ in $8 \mathrm{~ms}$ - much more quickly than most previously reported sensors. When external pressure was removed, the pressure sensor returned to its initial state in $11 \mathrm{~ms}$ - a shorter recovery time than that reported for any other sensor. This excellent response time is due to the liquid, and thus mobile, nature of the $\mathrm{BmimSbF}_{6}$ in the network.

The stability of the $70 \mathrm{phr} \mathrm{BmimSbF}_{6}$-loaded sensor was tested by multiple applications of a cyclic high pressure of $40 \mathrm{kPa}(1.0 \mathrm{~N})$. As depicted in SI Figure S8, the responsive signals were highly consistent under cyclic pressures. The voltage changes upon a step increase of pressure from $2.4 \mathrm{kPa}(0.06 \mathrm{~N})$ to $46.8 \mathrm{kPa}(1.2 \mathrm{~N})$ were measured to investigate the response over a relatively wide pressure range. As shown in Figure 3d, the voltage change dramatically increased with rising pressure, demonstrating the $\mathrm{BmimSbF}_{6}$-loaded pressure sensor's capacity to distinguish various pressures via stable sensing signals. It also can be seen that the pressure sensor responds quickly to an applied pressure, and returns to the initial state in short time when the external pressure was removed.

An ideal pressure sensor with excellent performance should possess high sensitivity, wide linearity range, and short response time. The 3D chart presented in Figure 4a shows a sensing characteristics comparison of the pressure sensor developed within this study and pressure sensors with different fillers reported previously. ${ }^{[5,7,10,16,18]}$ By the overall evaluation of the sensitivity, response time and linearity range, the novel pressure sensor in this work is an overall better sensor. While it does not have the highest sensitivity, its response time is 75 times faster than that of a carbon nanotubes / hydrophobically associated hydrogel sensor, ${ }^{[5 a]} 15$ times faster than that of the graphene-paper pressure sensor, ${ }^{[7 b]}$ and 3 times faster than that of the ionic gel 


\section{WILEY-VCH}

pressure sensor. ${ }^{[16]}$ Moreover, the $\mathrm{BmimSbF}_{6}$-loaded sensor also has a wide linear pressure range. These results are also listed in Figure $\mathbf{4 b}$.

Furthermore, not only can the $70 \mathrm{phr} \mathrm{BmimSbF}_{6}$ loaded film be used as an iontronic pressure sensor, but it is also an excellent candidate for a capacitive pressure sensor. The dielectric permittivity, which is a critical parameter for the sensitivity of the capacitive pressure sensor, was also tested here. Unlike conventional PDMS elastomers, BmimSbF-loaded films exhibit high permittivity, as shown in SI Figure S9. The dielectric permittivity at $10^{6} \mathrm{~Hz}$ increased from 2.24 for the pure PDMS elastomer to 10.34 for the sample with $70 \mathrm{phr}$ $\mathrm{BmimSbF}_{6}$-i.e. almost 5-fold. Storage permittivities of $\mathrm{BmimSbF}_{6}$-loaded films are also presented in SI Table S2.

\section{Conclusion}

In summary, a novel flexible pressure sensor was constructed by incorporating $\mathrm{BmimSbF}_{6}$ into PDMS. The ionic pressure sensor thus produced exhibited outstanding mechanical properties, fast response, wide detection range, and high sensitivity. Furthermore, the $70 \mathrm{phr} \mathrm{BmimSbF}_{6}$ loaded pressure sensor showed high pressurizing cycling stability under high applied pressure, as well as the ability to distinguish various pressures via stable sensing signals over the pressure range from $0 \mathrm{kPa}$ to $50 \mathrm{kPa}$. Its response time of $8 \mathrm{~ms}$ to a pressure input of $1.6 \mathrm{kPa}(0.04 \mathrm{~N})$ is much shorter than that of most previously reported pressure sensors, and its recovery time of $11 \mathrm{~ms}$ is the shortest yet reported. This novel pressure sensor's excellent comprehensive performance and facile fabrication process mean that is has great potential for healthcare and smart wearable device applications.

\section{Acknowledgements}

This work was supported by the Department of Chemical and Biochemical Engineering, Technical University of Denmark, the National Natural Science Foundation of China (Grant No. 21776276.) and Zhengzhou High Level Talent (20180300045). 


\section{WILEY-VCH}

\section{Supporting information}

Supporting information is available.

\section{Conflict of interest}

The authors declare no conflicts of interest.

\section{References}

[1] a) J. Zhou, X. Xu, Y. Xin, G. Lubineau, Adv. Funct. Mater. 2018, 28 (16), 1705591; b) M. O. F. Emon, F. Alkadi, D. G. Philip, D. H. Kim, K.C. Lee, J. W. Choi, Addit. Manuf. 2019, 28, 629-638.

[2] a) S. Gong, W. Schwalb, Y. Wang, Y. Chen, Y. Tang, J. Si, B. Shirinzadeh, W. Cheng, Nat. Commun. 2014, 5, 3132; b) X. Liao, Z. Zhang, Z. Kang, F. Gao, Q. Liao, Y. Zhang, Mater. Horiz. 2017, 4 (3), 502-510.

[3] a) M. Cakici, R. R. Kakarla, F. Alonso-Marroquin, Chem. Eng. J. 2017, 309, 151-158; b) L. Peng, Y. Zhu, H. Li, G. Yu, Small 2016, 12 (45), 6183-6199; b) Y. Sun, R. B. Sills, X. Hu, Z. W. Seh, X. Xiao, H. Xu, W. Luo, H. Jin, Y. Xin, T. Li, Z. Zhang, J. Zhou, W. Cai, Y. Huang, Y. Cui, Nano. Lett. 2015, 15 (6), 3899-906.

[4] Y. Zang, F. Zhang, C. Di, D. Zhu, Mater. Horiz. 2015, 2 (2), 140-156.

[5] a) Z. Qin, X. Sun, Q. Yu, H. Zhang, X. Wu, M. Yao, W. Liu, F. Yao, J. Li, ACS Appl. Mater. Inter. 2020, 12 (4), 4944-4953; b) Z. Zhang, Y. Zhang, X. Jiang, H. Bukhari, Z. Zhang, W. Han, E. Xie, Carbon 2019, 155, 71-76.

[6] a) S. Lee, A. Reuveny, J. Reeder, S. Lee, H. Jin, Q. Liu, T. Yokota, T. Sekitani, T. Isoyama, Y. Abe, Z. Suo, T. Someya, Nat Nanotechnol 2016, 11 (5), 472-8; b) G. Topcu, M. M. Demir, Sensor Actuat. A-Phy. 2019, 295, 237-243.

[7] a) S. Wan, H. Bi, Y. Zhou, X. Xie, S. Su, K. Yin, L. Sun, Carbon 2017, 114, 209-216; b) L. Q. Tao, K. N. Zhang, H. Tian, Y. Liu, D. Y. Wang, Y. Q. Chen, Y. Yang, T. L. Ren, ACS Nano. 2017, $11(9), 8790-8795$. 


\section{WILEY-VCH}

[8] a) M. Segev-Bar, A. Landman, M. Nir-Shapira, G. Shuster, H. Haick, ACS Appl. Mater. Inter. 2013, 5 (12), 5531-41; b) N. M. Sangeetha, N. Decorde, B. Viallet, G. Viau, L. Ressier, J. Phy. Chem. C 2013, 117 (4), 1935-1940.

[9] J. Heikenfeld, A. Jajack, J. Rogers, P. Gutruf, L. Tian, T. Pan, R. Li, M. Khine, J. Kim, J. Wang, J. Kim, Lab Chip 2018, 18 (2), 217-248.

[10] J. Lee, J. Kim, Y. Shin, I. Jung, Compos. Part. B Eng. 2019, 177, 107364.

[11] Y. Song, H. Chen, Z. Su, X. Chen, L. Miao, J. Zhang, X. Cheng, H. Zhang, Small 2017, 13 (39), 1702091.

[12] a) F. B. Madsen, S. Zakaria, L. Yu, A. L. Skov, Adv. Eng. Mater. 2016, 18 (7), 1154-1165; b)

A. L. Skov, L. Yu, Adv. Eng. Mater. 2018, 20 (5), 1700762.

[13] E. Ogliani, L. Yu, P. Mazurek, A. L. Skov, Polym. Degrad. Stabil. 2018, 157, 175-180.

[14] X. Yang, Y. Wang, X. Qing, Sensors (Basel) 2018, 18 (7), 2395.

[15] a) Z. Zhu, X. He, Q. He, X. Fang, Q. Hu, H. Chen, J. Appl. Phy. 2019, 125 (2), 024901; b) X. Yang, Y. Wang, H. Sun, X. Qing, Sensor Actuat. A Phy. 2019, 285, 67-72.

[16] S. H. Cho, S. W. Lee, S. Yu, H. Kim, S. Chang, D. Kang, I. Hwang, H. S. Kang, B. Jeong, E. H. Kim, S. M. Cho, K. L. Kim, H. Lee, W. Shim, C. Park, ACS Appl. Mater. Inter. 2017, 9 (11), 10128-10135.

[17] X. Liu, L. Yu, Y. Nie, A. L. Skov, Adv. Eng. Mater.2019, 21 (10), 1900481.

[18] a) X. Dong, Y. Wei, S. Chen, Y. Lin, L. Liu, J. Li, Compos. Sci. Technol. 2018, 155, 108-116; b) J. Yang, Y. Ye, X. Li, X. Lü, R. Chen, Compos. Sci. Technol. 2018, 164, 187-194; c) A. Tewari, S. Gandla, S. Bohm, C. R. McNeill, D. Gupta, ACS Appl. Mater. Inter. 2018, 10 (6), 5185-5195; d) O. Atalay, A. Atalay, J. Gafford, C. Walsh, Adv. Mater. Technol. 2018, 3 (1),1700237. 


\section{WILEY-VCH}

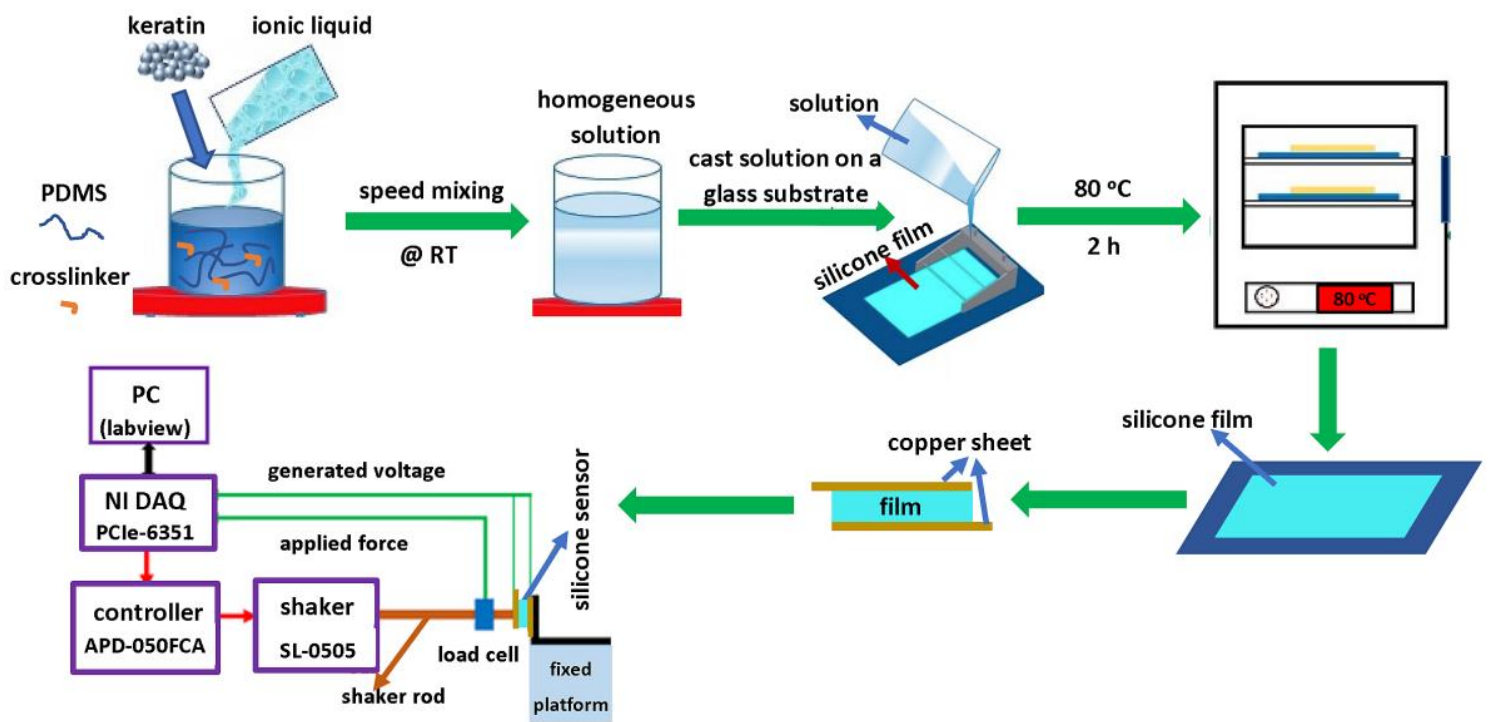

Figure 1 Fabrication process and test setup of the $\mathrm{BmimSbF}_{6}$-loaded pressure sensor.
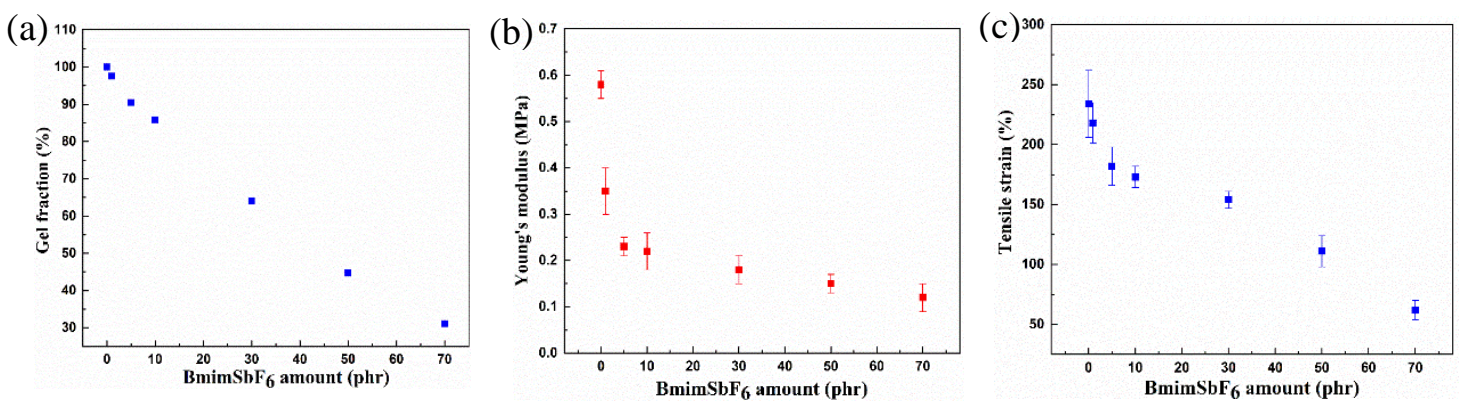

Figure 2 a) Gel fractions, b)Young's moduli and c) tensile strains of films with different amounts of $\mathrm{BmimSbF}_{6}$. 

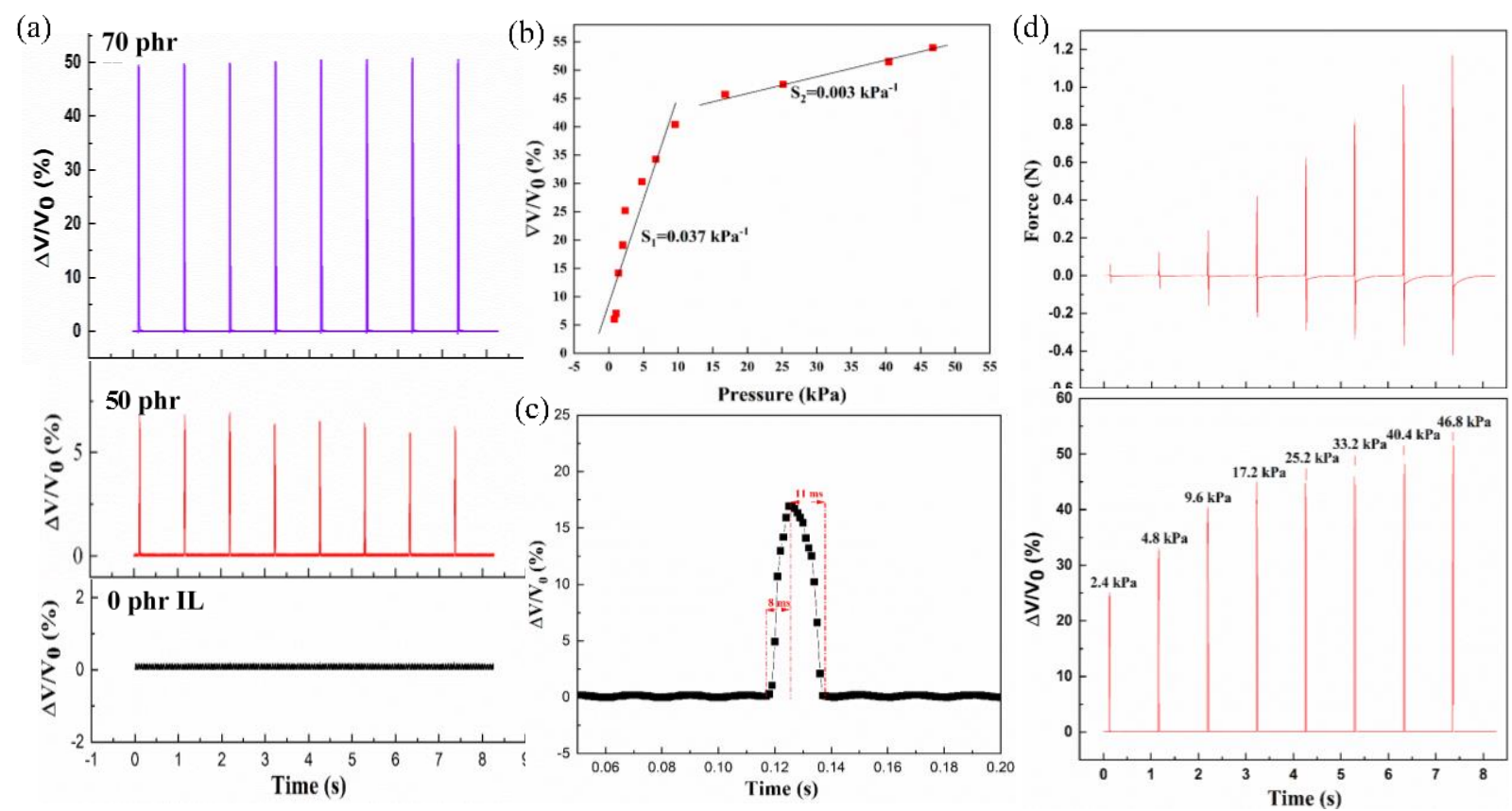

Figure 3 a) Voltage changes for films with different loadings of $\mathrm{BmimSbF}_{6}$ in response to a pressure input of $40 \mathrm{kPa}(1.0 \mathrm{~N})$; b) Sensitivity of film with $70 \mathrm{phr} \mathrm{BmimSbF}_{6}$ in response to varying pressures; c) Voltage change of $70 \mathrm{phr} \mathrm{BmimSbF}_{6}$-loaded film after a sudden increase pressure from $0 \mathrm{kPa}$ to $1.6 \mathrm{kPa}(0.04 \mathrm{~N})$; d) Applied force and relative voltage changes in response to a step-wise increase of pressure from $2.4 \mathrm{kPa}(0.06 \mathrm{~N})$ to $46.8 \mathrm{kPa}(1.2 \mathrm{~N})$.

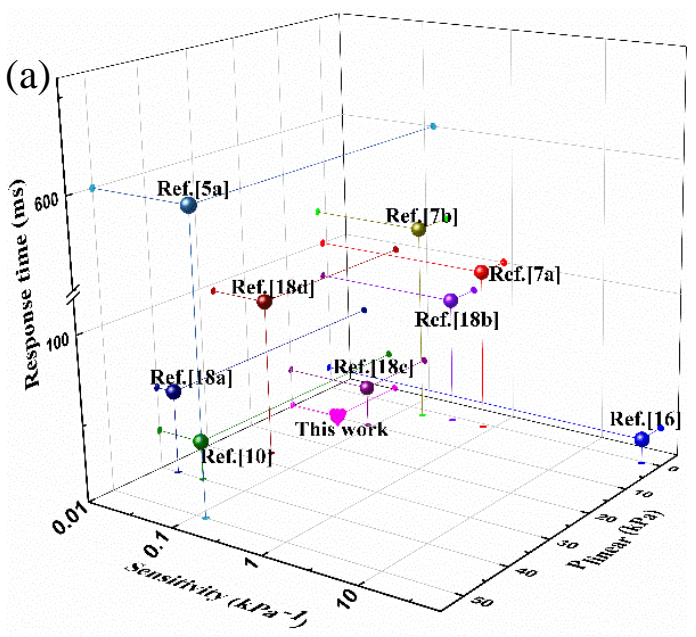

(b)

\begin{tabular}{|c|c|c|c|c|}
\hline Reference & $\begin{array}{c}\text { Sensitivity } \\
\left(\mathrm{kPa}^{-1}\right)\end{array}$ & $\begin{array}{c}\text { Response time } \\
(\mathrm{ms})\end{array}$ & $\begin{array}{l}\text { Linear pressure } \\
\text { Range (kPa) }\end{array}$ & Fillers \\
\hline This work & 0.037 & 8 & 10 & {$[\mathrm{Bmim}]\left[\mathrm{SbF}_{6}\right]$} \\
\hline Ref. [5a] & 0.127 & 600 & 50 & $\begin{array}{l}\text { Hydrophobic carbon } \\
\text { nanotubes }\end{array}$ \\
\hline $\operatorname{Ref} .[7 \mathrm{a}]$ & 0.8 & 100 & 1 & Graphene Oxide \\
\hline Ref. [7b] & 0.17 & 120 & 2 & Graphene \\
\hline Ref. [10] & 0.032 & 29 & 40 & Carbon nanotubes \\
\hline Ref.[16] & 41.64 & 21 & 0.5 & [EMI][TFSA] \\
\hline Ref. [18a] & 0.016 & 54 & 40 & $\begin{array}{l}\text { Graphene/Silver } \\
\text { nanowires }\end{array}$ \\
\hline Ref. [18b] & 0.36 & 80 & 1.25 & $\begin{array}{l}\text { Reduced graphene } \\
\text { oxide }\end{array}$ \\
\hline Ref. [18c] & 0.088 & 30 & 10 & MWNT-rGO \\
\hline Ref. [18d] & 0.042 & 96 & 27 & Sugar granules \\
\hline
\end{tabular}

Figure 4 a) 3D chart of a comparison of three key pressure sensor parameters: sensitivity, response time, and linear pressure range; b) Characteristics of reported pressure sensors. 


\section{Click here to access/download Supporting Information \\ Support information.docx}


Click here to access/download Supporting Information Table of content-Xue.docx 